\title{
loT and BDA in the Brazilian future logistics 4.0 scenario
}

\author{
Jobel Santos Correa ${ }^{a *}$ (D), Mauro Sampaio ${ }^{\mathrm{b}}$ (D), Rodrigo de Casto Barros $^{\mathrm{b}}$ (D), \\ Wilson de Castro Hilsdorf ${ }^{b}$ \\ aFaculdade Estácio de Santo André, Santo André, SP, Brasil

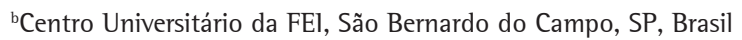 \\ *jobel.correa@gmail.com
}

\begin{abstract}
Paper aims: This paper aims to identify the degree of interest and expected return time on investment in lnternet of Things (loT) and Big Data Analytics (BDA) technologies by Brazilian logistics companies.

Originality: A logistics system that meets the requirements imposed by lndustry 4.0 is known as Logistics 4.0. According to the current scientific literature, loT and BDA technologies are the most promising for the logistics 4.0 applications. Studies on the adoption of these technologies in Brazil are still embryonic and this paper collaborates to narrow this knowledge gap.
\end{abstract}

Research method: Exploratory research was conducted using the quantitative approach.

Main findings: The evidence of the interest in investment in loT and BDA by Brazilian logistics companies, confirming the current literature.

Implications for theory and practice: The identification of the intended practical applications for lot and BDA, as well as the expected difficulties in the implementation of these Technologies.

\section{Keywords}

Logistics. Supply chain. Internet of things. Big data analytics. Industry 4.0.

How to cite this article: Correa, J. S., Sampaio, M., Barros, R. C., \& Hilsdorf, W. C. (2020). loT and BDA in the Brazilian future logistics 4.0 scenario. Production, 30, e20190102. https://doi.org/10.1590/0103-6513.20190102

Received: Aug. 14, 2019; Accepted: Feb. 10, 2020.

\section{Introduction}

Logistics is an important component of the supply chain management. A logistics system manages the flow of materials and information, managing the movement and efficient storage of data, goods, and services. The goal of a logistics system is to deliver finished products to the end customer at appropriate level of service and quality, with the lowest possible costs (Strandhagen et al., 2017). For Hofmann \& Rüsch (2017), Industry 4.0 is a current theme, as it has potential to affect several industrial segments, transforming the way products are designed, manufactured, paid and delivered to the end customer. For the full potential promised by lndustry 4.0 to be achieved, a logistics system aligned with its concepts is necessary. Logistics 4.0 describes the application of emerging technologies, seeking efficiency improvements in logistics processes (Pfohl et al., 2015). According to Witkowski (2017), several emerging technologies can be applied to the Logistics 4.0 concept. According to literature, the most promising emerging technologies in this field are Internet of Things (loT) and Big Data Analytics (BDA).

There are few studies on the application of emerging technologies in logistics, as reported by Pfohl et al. (2015, p.44]), "[...] organizations need to understand how logistics and supply chain will be impacted by emerging technologies". Lack of knowledge of the Logistics 4.0 implementation process may generate several 
problems, such as: little information exchange among different sectors, little diffusion of knowledge, and little participation from the academic community in the development of the sector. In Brazil, the effectiveness of Logistics 4.0 is unknown, as well as its induction variables. Bearing this gap in mind, this research intends to contribute in revealing some of these aspects.

This study aims to identify the degree of interest and expected return time on investment in Internet of Things (loT) and Big Data Analytics (BDA) technologies by Brazilian logistics companies

The remainder of this paper is organized as follows. In Section 2, we summarize the literature related to Logistics 4.0. This is followed by a presentation of the method. In following section, we present in details: shows the results obtained in the field research and includes the discussion of results. Finally, the fifth section presents the final conclusion, research limitations, and possible future studies.

\section{Literature review}

\subsection{Logistics}

Different authors present different concepts and definitions for the logistics activity. This study adopted the most modern and widely accepted concept of the Supply Chain Management Professionals Council, which defines logistics as: "Part of the supply chain management that plans, implements and controls the efficient and effective flow, and reverses the flow and storage of goods, services, and related information between the point of origin and the point of consumption to meet customer requirements" (Council of Supply Chain Management Professionals, 2018, p.01).

Logistics has undergone three revolutionary changes in the past, namely: the first change (logistics 1.0) occurred at the end of the nineteenth and beginning of the twentieth centuries with the introduction of steam mechanization on ships and trains, replacing men and animal traction as a means of transport. The second change (logistic 2.0) occurred with the discovery of electric power and the introduction of mass production, leading to the automation of cargo handling in the middle of the beginning of the twentieth century until the end of World War 11. The third one (logistics 3.0) occurred with the systematization of logistics management and the introduction of micro-information and communication technologies in the 1980s (Wang et al., 2016).

According to Thoben et al. (2017), Industry 4.0 is characterized by the introduction of new manufacture technologies, which allows factories to have vertically and horizontally integrated production, flexible processes that allow individualized mass production, intelligent machines that exchange data between each other and control the production and logistics processes by themselves. Drees (2016) points out that Industry 4.0 results in the digitization of industrial processes. Digitization requires new logistics solutions based on emerging technologies that will affect current transport and management of supply chains. The set of these logistic solutions is called Logistics 4.0 and these solutions are a prerequisite for the existence of Industry 4.0. The existence of Logistics 4.0 depends on different emerging technologies linked to the ability to capture and process large amounts of data and to make actions based on information resulting from this processing (Wang et al., 2016).

\subsection{Emerging technologies linked to logistics 4.0}

Literature points to the feasibility of use in logistics and in the supply chain management of several emerging technologies. Table 1 summarizes the authors who have quoted loT and BDA technologies as widely applicable in logistics.

Table 1. References on the applicability of loT and BDA technologies in logistics.

\begin{tabular}{|c|c|c|c|c|c|c|c|c|c|}
\hline & $\begin{array}{l}\text { Kim \& Kim } \\
\text { (2016) }\end{array}$ & $\begin{array}{l}\text { Lu et al. } \\
\text { (2018) }\end{array}$ & $\begin{array}{l}\text { Gubbi et al. } \\
\text { (2013) }\end{array}$ & $\begin{array}{l}\text { Goldsby \& } \\
\text { Zinn (2016) }\end{array}$ & $\begin{array}{l}\text { Zhu et al. } \\
\text { (2018) }\end{array}$ & $\begin{array}{l}\text { Rossmann et al. } \\
\text { (2017) }\end{array}$ & $\begin{array}{l}\text { Wang et al. } \\
\text { (2016) }\end{array}$ & $\begin{array}{c}\text { Richey } \\
\text { Junior et al. } \\
\text { (2016) }\end{array}$ & $\begin{array}{c}\text { Waller \& } \\
\text { Fawcett } \\
\text { (2013) }\end{array}$ \\
\hline loT & $\bullet$ & $\bullet$ & $\bullet$ & $\bullet$ & & & & & \\
\hline BDA & & & & & • & • & • & • & • \\
\hline
\end{tabular}

\subsection{Internet of Things (loT)}

According to Lu et al. (2018, p.01) "The Internet of Things is a technological paradigm that aims to connect anything and anyone anytime and anywhere, giving rise to new and innovative services and applications". Gubbi et al. (2013) reported that this connection is given by the use of a worldwide network of interconnected 
objects that can be exclusively addressed based on standard communication protocols. Gubbi et al. (2013), Kim \& Kim (2016), Goldsby \& Zinn (2016) and Lu et al. (2018) are among the authors who quote loT applications in Logistics.

According to Kim \& Kim (2016), loT technology applied to Logistics is the most promising loT application due to its strong market potential and promise of a considerable improvement in the logistics system of the supply chain of companies. For Uckelmann et al. (2011), The Internet of Things is a concept in which the virtual world of information technology perfectly integrates with the real world of "things".

According to Oppitz \& Tomsu (2018), the The Internet of Things refers to the software, sensors and devices connected in computer networks to allow the exchange of data with other devices, systems, applications and users, whose aim is to create a network infrastructure to facilitate the transit of goods, services and information. loT's continuous development is related to cloud computing, big data, and other advanced computing technologies (Majeed \& Rupasinghe, 2017). Literature identifies the following loT applications in Logistics:

a) Warehouse Management: Goldsby \& Zinn (2016) reported that one of the major changes in logistics systems and supply chain management is caused by the adoption of loT technology in warehouse management. loT infrastructure provides a collaborative storage platform that facilitates the sharing of physical space and logistical information across multiple companies, helping them to track inventory efficiently, improving traceability and transparency of operations (Lu et al., 2018);

b) Traffic monitoring: traffic monitoring can be performed using GPS detection devices installed in vehicles and in constant communication via loT devices network (Zanella et al., 2014);

c) Fleet management: fleet management is a critical part of the transportation and logistics sector as it involves the movement of assets and equipment. By implementing loT applications to maintain and manage transportation and fleet, costs can be reduced and time saved as loT devices provide real-time information on fleet and vehicle conditions individually (Macaulay et al., 2015);

d) Visibility: the transportation and logistics business depends on the proper and timely supply chain management. loT technology can synchronize existing information and product flows into a supply chain, integrating data from supply chain members to provide complete and transparent information, improving visibility and efficiency of all supply chain members (Tu, 2018). Figure 1 shows an example of visibility in the supply chain using loT technology.

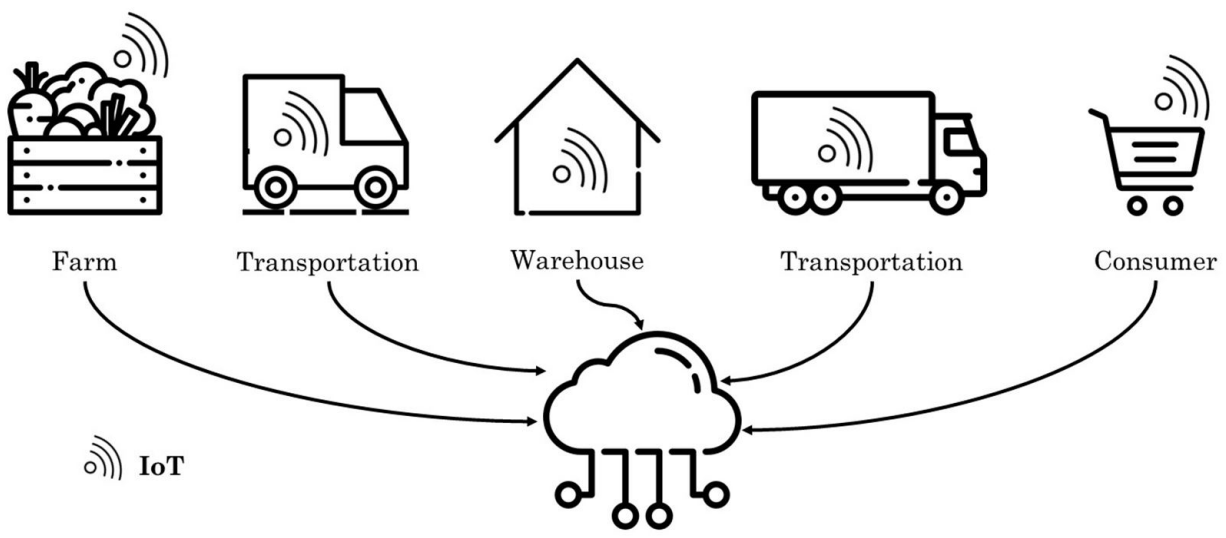

Cloud Integrated to Big Data Analytics

Figure 1 . Supply chain availability with the use of loT devices.

\subsection{Big Data Analytics (BDA)}

The increasing amount of available data has created the need for the development of business intelligence technologies that are summarized under the term big data analytics (Rossmann et al., 2017). According to Tiwari et al. (2018), big data can be defined as large and complex datasets with current size of an exabyte $\left(10^{18}\right.$ bytes), which could reach the size of an zettabyte ( $10^{21}$ bytes) per year in some years, due to massive adoption of mobile devices, cameras, microphones and loT devices (Zhong et al., 2016). 
Waller \& Fawcett (2013), Richey Junior et al. (2016), Wang et al. (2016), Rossmann et al. (2017) and Zhu et al. (2018) are among authors mentioning big data applications in logistics. Rossmann et al. (2017) reported that BDA is especially relevant to logistics and supply chain management because it provides tools to support decision making in increasingly global and dynamic environments. However, this relevance creates enormous challenges for organizations that would like to reap the rewards of analyzing this massive big data flow, such as market trends, customer buying patterns, maintenance cycles, ways of reducing costs and enabling more targeted business decisions (Wang et al., 2016).

Richey Junior et al. (2016) define big data into four (4) dimensions: volume, velocity, variety and veracity, see Figure 2. A fifth dimension, called value, was added by Tiwari et al. (2018) and the inclusion of the fifth dimension created the concept called " $5 \mathrm{~V}$ ". The volume dimension deals with the amount of data, the velocity dimension is important for decision-making, variety dimension deals with the heterogeneity of data sources, veracity dimension eliminates invalid data, and finally, value dimension deals with transforming big data into value added for the organization. BDA deals with " $5 \mathrm{~V}$ ", allowing managing these new and potentially valuable datasets using descriptive analytics, predictive analytics and prescriptive analytics (Wang et al., 2016).

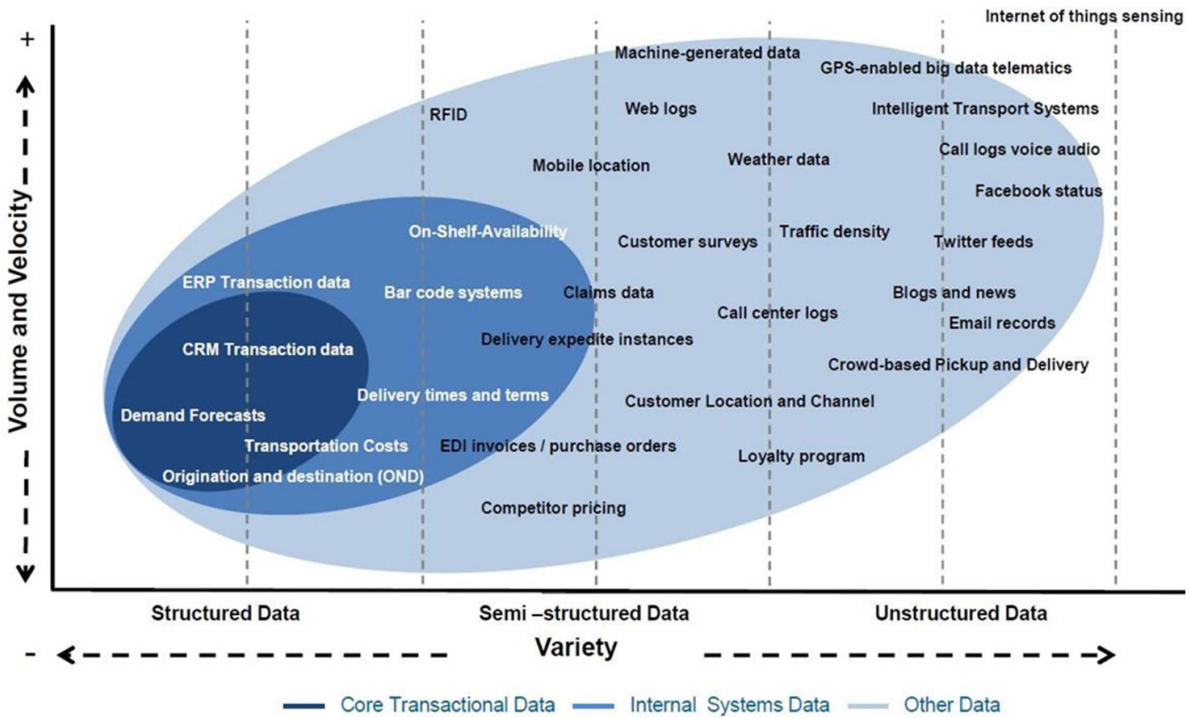

Figure 2. Big Data 5V concept applied to supply chain management (SCM).

According to Vassakis et al. (2018), descriptive analytics is more commonly used and better understood because it is based on historical data and is a source of information about what occurred in the past and explores this information to identify problems and opportunities within the functions and processes of organizations.

Predictive analytics deals with the question of what is likely to occur, exploring data patterns through the use of statistics, simulations and algorithms (Tiwari et al., 2018). Waller \& Fawcett (2013) reported that predictive analytics uses quantitative and quantitative methods to estimate, for example, the flow behavior and storage of inventories, as well as associated cost and service levels. The incorporation of predictive analytics into BDA analytics can help to recognize patterns and trends and predict perturbations that may affect transport modes (Zhu et al., 2018).

Finally, Wang et al. (2016) reported that prescriptive analytics involves the use of mathematical data and algorithms to determine and evaluate alternative decisions that include objectives and requirements characterized by high volume and complexity of data, with the aim of improving business performance, overcoming competitors and gaining competitive advantage.

\section{Methodology}

\subsection{Study type}

This online survey was a cross-sectional study, with a non-probabilistic sample taken from the main Brazilian companies from different areas, considering they had a developed program or a logistics 4.0 process under development. In these organizations, we assessed the existence of the logistics 4.0 process, 
and through a quantitative research, we sought to measure the level of maturity of this process, as well as the variables which affect the performance of the process. Exploratory research is carried out in the initial stages of the phenomenon emergence, and the main aim of the exploratory research is to obtain insights about the phenomenon, which will serve as a future basis for a more detailed research (Sampieri et al., 2013). According to Forza (2002), survey-type studies can be conducted to contribute to the general knowledge in a particular area of interest.

The participants of the process were the object of this research, such as coordinators, managers, directors (generally associated with logistics areas), and participants of the process (supervisors).

The choice of the online survey method occurs because this method presents a known form of access and information collection, since respondents are accustomed to send and receive information via the internet. According to Sampieri et al. (2013), opinion research survey is adequate for the following reasons:
a) allows for easy data collection;
b) data collected can be easily quantified;
c) allows the use of measures developed and validated in previous studies.

\subsection{Operationalization of variables}

The research form adopted in this work was based on the model used in the Big Data Analytics in Supply Chain research (Rogers, 2017). From this work, the scales for the measurement of variables gain in the financial investment and time to obtain gain in the financial investment in the emerging technologies mentioned here were obtained. The scales of measurement of the degree of quality and integration of data were based on scales developed by Dong et al. (2001). This research used scales of measurement which had already been developed and tested in the literature, adjusted to the current context and language. These measures had previously been tested in the literature with satisfactory results, which encouraged the researcher to follow this path.

\subsection{Operational definition of variables}

Table 2 presents the operational definition of variables and their respective metric scales.

Table 2. Operational definition of variables.

\begin{tabular}{|c|c|c|c|}
\hline Variable & Measure & Scale & Source \\
\hline Gain & $\begin{array}{l}\text { Expected gain with loT investment } \\
\text { Expected gain with BDA investment } \\
\text { Expected gain with cloud investment } \\
\text { Expected gain with blockchain investment } \\
\text { Expected gain with 3D printing investment } \\
\text { Expected gain with crowdsourcing investment }\end{array}$ & $\begin{array}{c}\text { 5-point likert scale: } \\
\text { [1] No gain } \\
\text { Up to } \\
\text { [5] High gain. }\end{array}$ & Rogers (2017) \\
\hline Time & $\begin{array}{l}\text { Expected time to obtain gains with investment in } \\
\text { Expected time to obtain gains with BDA investment } \\
\text { Expected time to obtain gains with cloud investment } \\
\text { Expected time to obtain gains with blockchain investment } \\
\text { Expected time to obtain gains with 3D printing investment } \\
\text { Expected time to obtain gains with crowdsourcing investment }\end{array}$ & $\begin{array}{c}\text { 5-point Likert scale: } \\
\text { [1] No impact } \\
\text { Up to } \\
\text { [5] Long term. }\end{array}$ & Rogers (2017) \\
\hline Quality of data & $\begin{array}{l}\text { My company's data are stored in appropriate format (reliable) } \\
1 \text { can have easy access to my company's data (accessible) } \\
\text { All organizational functions have the same data (unique) } \\
\text { My company's data can be exchanged with my supply chain (available) } \\
\text { My company already exchanges data and information with suppliers and / or clients } \\
\text { (collaborative) }\end{array}$ & $\begin{array}{c}\text { 5-point Likert scale: } \\
\text { [1] Fully disagree } \\
\text { Up to } \\
\text { [5] Fully agree }\end{array}$ & $\begin{array}{l}\text { Dong et al. } \\
\text { (2001) }\end{array}$ \\
\hline $\begin{array}{l}\text { Integration of } \\
\text { data }\end{array}$ & $\begin{array}{l}\text { My company's computer systems communicate with customers and / or suppliers } \\
\text { My company shares data with customers and / or suppliers } \\
\text { My company shares cost savings with customers and / or suppliers } \\
\text { My company works with suppliers aiming to improve of processes }\end{array}$ & $\begin{array}{l}\text { 5-point Likert scale: } \\
\text { [1] Fully disagree } \\
\text { Up to } \\
\text { [5] Fully agree }\end{array}$ & $\begin{array}{c}\text { Dong et al. } \\
(2001)\end{array}$ \\
\hline
\end{tabular}




\section{4. procedures for translation and adaptation of scales used}

All research instruments were originally in English. Texts were translated into Portuguese by two professional translators and then compared by two experts, fluent in English, to ensure accuracy with original texts and constructs. After this work, the text was translated again into English, a task carried out by another bilingual translator. This version was compared with the original texts in the English language. Comparison was considered satisfactory and can then be developed to the research instrument pre-test.

\subsection{Research instrument pre-test}

The survey questionnaire was validated by three specialists in the area of logistics and supply chain management (two executive directors and one national manager in their respective companies). This fine-tuning enabled verifying inconsistencies in questions, double questions and determining the correct appearance of the form, correcting the research tool before sending it to respondents (Sampieri et al., 2013). In addition, the pre-test validated the application of the questionnaire, via the internet, using the Survey Monkey research site.

\subsection{Population and sample}

The population selected consisted of companies that had a developed program or a Logistics 4.0 process under development have. A non-probabilistic sample was carried out as we did not have a database available listing all these professionals. These professionals were identified through the authors partnered with Tecnologistica, a leading logistics practitioner journal in Brazil, to develop a sampling frame. Tecnologística was selected due to its nationwide readership that includes over 8,000 companies from a variety of industries and job titles. Tecnologística sent an email to each of its subscribers introducing the survey and providing a link to the survey for those subscribers who might be interested in participating. Although the sample is non-probabilistic, its elements are legitimate representatives of the main Brazilian companies and able to provide the necessary data to the survey. A survey was conducted between August and November of 2018 and presented 108 valid responses.

\section{Results}

\subsection{Profile of responding companies}

Table 3 shows the profile of companies that responded to the survey. The categorization of company size follows the IBGE classification.

Table 3. Profile of responding companies.

\begin{tabular}{|c|c|c|}
\hline Profile of responding companies & frequency (total 108) & $\%$ \\
\hline \multicolumn{3}{|l|}{ Company size } \\
\hline Large size ${ }^{1}$ & 37 & 34.3 \\
\hline Medium size ${ }^{2}$ & 21 & 19.4 \\
\hline Small size $^{3}$ & 27 & 25.0 \\
\hline Micro-company ${ }^{4}$ & 23 & 21.3 \\
\hline \multicolumn{3}{|l|}{ Sector of company operation } \\
\hline e-Commerce & 8 & 7.4 \\
\hline Industry & 25 & 23.1 \\
\hline Retail & 7 & 6.5 \\
\hline Logistic Services ${ }^{5}$ & 35 & 32.4 \\
\hline Other Services ${ }^{6}$ & 27 & 25.0 \\
\hline Others & 6 & 5.6 \\
\hline \multicolumn{3}{|l|}{ Region of Brazil where company headquarters is located } \\
\hline Northern & 0 & 0.0 \\
\hline Northeastern & 6 & 5.6 \\
\hline Mid-western & 3 & 2.8 \\
\hline Southeastern & 72 & 66.7 \\
\hline Southern & 27 & 25.0 \\
\hline
\end{tabular}

[1] Over 100 employees for commerce and services and over 500 employees for lndustry; [2] From 50 to 99 employees for commerce and services and from 100 to 499 employees for industry; [3] From 10 to 49 employees for commerce and services and from 20 to 99 employees for industry; [4] Up to 9 employees for commerce and services and up to 19 employees for industry; [5] lncludes warehousing, transportation, fleet management, risk management, etc; [6] Includes consulting, information technology (IT), software development, etc. 
Large companies make up the largest group of respondents, with 34\% of questionnaires filled out followed by small companies, with $25 \%$ of responses. The number of small, medium-size companies and micro-companies is similar, which shows that emerging technologies are of interest to companies of all sizes. Regarding the sector of company operation, the majority of respondents belong to the logistics services sector (which includes storage, transportation, fleet management, risk management companies and others), with 32\% responses, accompanied by other services (consultancies, IT companies, software development, etc.), with 25\% of responses, which shows that the majority of responses came from large companies of the logistics sector. Headquarters or main office is located in the southeastern region of Brazil for 67\% of responding companies, followed by the southern region, with $25 \%$ of responses.

Table 4 summarizes the profile of survey respondents regarding the position in the company and age group.

The survey was responded mainly by managers, with $26 \%$ of responses, followed by vice-presidents or directors, with $21 \%$ participation and by presidents, with $13 \%$ of responses. These results show that more than $60 \%$ of respondents belong to the top management of companies, which shows a holistic view of the results obtained. Regarding age group, the largest group is composed of people aged 41-50 years, with 42\% of responses. The second largest group concentrates people aged 31-40 years, with 30\% of responses, therefore, in general, respondents are experienced professionals.

Table 4. Profile of respondents.

\begin{tabular}{lcc}
\hline \multicolumn{1}{c}{ Profile of respondents } & frequency (total 108) & $\%$ \\
\hline Position of respondent in the company & & 13.0 \\
President & 23 & 21.3 \\
Vice-President/ Director & 28 & 25.9 \\
Manager & 5 & 4.6 \\
Engineer & 18 & 16.7 \\
Analyst/ Specialist & 13 & 12.0 \\
Supervisor/ Coordinator & 7 & 6.5 \\
Other & & 9.3 \\
Age group of respondents & 10 & 30.6 \\
21 to 30 years & 33 & 41.7 \\
31 to 40 years & 45 & 7.4 \\
41 to 50 years & 8 & 11.1 \\
51 to 60 years & 12 & \\
More than 60 years & & \\
\hline
\end{tabular}

\subsection{Interest in loT and BDA lnvestment}

Table 5 summarizes the interest of respondent companies in investing in loT and BDA technologies.

Table 5. Summary of the interest of companies in loT and BDA technologies.

\begin{tabular}{|c|c|c|c|c|}
\hline & \multicolumn{2}{|c|}{ loT } & \multicolumn{2}{|c|}{ BDA } \\
\hline & $f$ & $\%$ & f & $\%$ \\
\hline \multicolumn{5}{|l|}{ Does your company intend to invest? } \\
\hline Yes & 89 & 82.4 & 60 & 55.6 \\
\hline No & 19 & 17.6 & 48 & 44.4 \\
\hline \multicolumn{5}{|l|}{ When does your company intend to invest? } \\
\hline We have already invested & 70 & 64.8 & 35 & 32.4 \\
\hline We will invest in the short term (up to 1 year) & 13 & 12.0 & 19 & 17.6 \\
\hline We will invest in the medium term ( $2-5$ years) & 3 & 2.8 & 5 & 4.6 \\
\hline We will invest in the long term (over 5 years) & 3 & 2.8 & 1 & 0.9 \\
\hline There are no investment plans & 19 & 17.6 & 48 & 44.4 \\
\hline \multicolumn{5}{|l|}{ What is the main reason for the investment? } \\
\hline Maintaining competitive & 54 & 50.0 & 39 & 36.1 \\
\hline Anticipating against competition & 22 & 20.4 & 19 & 17.6 \\
\hline Customers' requirement & 11 & 10.2 & 2 & 1.9 \\
\hline Suppliers' requirement & 2 & 1.9 & 0 & 0.0 \\
\hline There are no investment plans & 19 & 17.6 & 48 & 44.4 \\
\hline
\end{tabular}

$f=$ frequency. 
Table 5 shows that companies show more interest in investing in loT, with 82\% of investment intent, followed by BDA with 56\% of interest. These same technologies already receive investments today, with 65\% of companies already investing in loT and 32\% of responding companies already investing in BDA.

The main reason for investing in emerging technologies is the maintenance of competitiveness, a response chosen 30\% of the time when the main reason for adopting emerging technologies is questioned, followed by anticipating the competition, reported 18\% of times when the same question was asked. Table 6 shows the intended applications for loT and BDA, presented in the research in an open question and grouped by similarity.

Table 6. Intended applications for emerging logistics technologies.

\begin{tabular}{lcc}
\hline Intended applications for emerging technologies in logistics & frequency (total 108) & $\%$ \\
\hline No response & 68 & 63.0 \\
BDA to lower operation costs & 5 & 4.6 \\
loT for tracking cargo & 3 & 2.8 \\
BDA to analyze consumer behavior & 2 & 1.9 \\
BDA for forecasting & 2 & 1.9 \\
\hline
\end{tabular}

The large number of respondents who left this question unanswered shows that the practical application of emerging technologies is not defined for most companies. Table 7 presents constraints to the adoption of emerging technologies cited by companies.

Table 7. Constraints to the adoption of emerging technologies.

\begin{tabular}{|c|c|c|c|c|}
\hline & \multicolumn{2}{|c|}{ loT } & \multicolumn{2}{|c|}{ BDA } \\
\hline & $\mathrm{f}^{\prime}$ & $\%$ & $f^{\prime}$ & $\%$ \\
\hline An adoption strategy is lacking & 15 & 11.2 & 17 & 14.0 \\
\hline High investment in software and hardware & 33 & 24.6 & 23 & 19.0 \\
\hline High investment in human resources & 17 & 12.7 & 22 & 18.2 \\
\hline Difficulty in understanding how technology adds value to the business & 16 & 11.9 & 9 & 7.4 \\
\hline Difficulty obtaining support or approval from top management & 6 & 4.5 & 2 & 1.7 \\
\hline There are no investment plans & 47 & 35.1 & 48 & 39.7 \\
\hline
\end{tabular}

$f=$ frequency; [1] This is a multiple-choice question, the respondent can mark more than one constraint option, so the sum of frequencies is not equal to the total of responses $(\mathrm{N}=108)$.

The high investment in software and hardware, followed by the high investment in human resources, are the most cited constraints when it comes to the adoption of emerging loT and BDA technologies. Table 8 provides additional constraints to the adoption of emerging technologies.

Table 8. Other constraints to the adoption of emerging technologies.

\begin{tabular}{lcc}
\hline & frequency (total 108) & $\%$ \\
\hline There are no other constraints & 72 & 67.3 \\
Lack of human resources & 11 & 10.3 \\
Lack of financial resources & 7 & 6.5 \\
Approval from company headquarters & 3 & 2.8 \\
Lack of professionals qualified in emerging technologies & 3 & 2.8 \\
Lack of ready-to-use BDA packages on the market & 3 & 2.8 \\
lnternet Infrastructure not compatible with emerging technologies & 2 & 1.9 \\
Customer culture & 1 & 0.9 \\
\hline
\end{tabular}

For the majority of respondents, there are no other constraints in addition to those mentioned in Table 5. Lack of human resources in 10\% of responses and the lack of financial resources in 6\% of responses are highlighted as constraints to the adoption of emerging technologies. Responses were written in open question in the search form and grouped by similarity.

\subsection{Individual interest in loT and BDA investment}

The intention of investing in loT and BDA was individually analyzed based on the degree of interest in the financial investment and the time of return of this investment. 


\subsubsection{Interest in loT investment}

Table 9 presents data related to the interest in loT investment.

Table 9 shows that the loT technology is interesting for 56\% of companies that responded the survey, that is, most respondents want to adopt loT technology. Thirty-seven companies already invest in loT, showing that the technology is already used by $34 \%$ of respondents.

Table 9. loT investment.

\begin{tabular}{lcc}
\multicolumn{1}{c}{ Internet of things investment } & frequency (total 108) & \% \\
\hline Does your company intend to invest in loT? & 61 & 56.5 \\
Yes & 47 & 43.5 \\
No & 37 & 34.3 \\
When does your company intend to invest in loT? & 9 & 8.3 \\
We have already invested & 12 & 11.1 \\
We will invest in the short term (up to 1 year) & 3 & 2.8 \\
We will invest in the medium term (2 - 5 years) & 47 & 43.5 \\
We will invest in the long term (over 5 years) & & 34.3 \\
There are no investment plans & 37 & 15.7 \\
What is the main reason for the investment? & 17 & 4.6 \\
Staying competitive & 5 & 1.9 \\
Anticipating against competition & 2 & 43.5 \\
Customers' requirement & 47 & \\
Suppliers' requirement & & \\
There are no investment plans & & \\
\hline
\end{tabular}

Maintaining competitiveness is the main reason for investing in loT for 34\% of respondents, the second reason is to anticipate competition, the response given by $16 \%$ of companies, showing that maintaining competitiveness is an important factor for the adoption of loT technology.

Table 10 analyzes the expectation of gain with loT investment and at what time companies believe that this gain will occur.

Table 10. Expectation of gain and return time for Internet of Things.

\begin{tabular}{|c|c|c|c|c|}
\hline \multicolumn{2}{|c|}{$\begin{array}{l}\text { What is the expectation of gain with loT investment and at what } \\
\text { time do you believe that this gain will occur? }\end{array}$} & \multirow{2}{*}{$\frac{N}{108}$} & \multirow{2}{*}{$\begin{array}{c}\text { Mean } \\
2.54\end{array}$} & \multirow{2}{*}{$\begin{array}{c}\text { Standard deviation } \\
1.997\end{array}$} \\
\hline All resnondents & Expected gain ${ }^{1}$ & & & \\
\hline All respondents & Expected time $^{2}$ & 108 & 1.49 & 1.411 \\
\hline
\end{tabular}

Table 10 shows that the expectation of gain is equal to 2.54, which is located between little and medium gain. The average expectation of gain is equal to 1.49, which is within short term. There is low expectation of financial gain associated with an immediate desire to achieve this gain. Table 11 presents the results of the ANOVA follow-up test to identify significant differences among group means using the Scheffe procedure, which is the most conservative method for this type of evaluation (Hair, 2005). This test aims to determine if there are significant differences in the average expectation of gain with loT investment when compared to company size. The null hypothesis is that the expectation of gain with loT investment is the same, regardless of company size.

Table 11 shows that there are no significant differences in the expectation of gain with loT investment for only medium-sized companies. The null hypothesis is then rejected at 5\% significance level for companies of this size and confirmed for large and small companies and micro-companies.

Table 12 presents the results of the ANOVA follow-up test to determine if there are significant differences in the expected time to obtain gains with loT investment. The null hypothesis is that the expectation of time to obtain gains with loT investment is the same, regardless of company size.

The results shown in Table 12 allow concluding that there are no significant differences in the expectation of time to obtain gains with loT investment when compared to company size. The null hypothesis, that the expectation of time to obtain gains with loT investment is the same regardless of company size, is then confirmed at 5\% significance level. 
Table 11. Expected gain with loT investment (ANOVA).

\begin{tabular}{|c|c|c|c|c|c|c|}
\hline \multicolumn{7}{|c|}{$\begin{array}{l}\text { Tests of effects among subjects (Scheffe) } \\
\text { Dependent variable: What is the expected gain with loT investment? }\end{array}$} \\
\hline Company Size & Origin & $\begin{array}{l}\text { Type III Sum of } \\
\text { Squares }\end{array}$ & $\begin{array}{l}\text { Degrees of } \\
\text { Freedom }\end{array}$ & Mean Square & $f$ & Sig. \\
\hline \multirow[t]{5}{*}{ Large size } & Corrected model & $25.039^{d}$ & 2 & 12.520 & 4.696 & 0.016 \\
\hline & Intercept & 351.050 & 1 & 351.050 & 131.688 & 0.000 \\
\hline & Error & 90.636 & 34 & 2.666 & & \\
\hline & Total & 492.000 & 37 & & & \\
\hline & Total corrected & 115.676 & 36 & & & \\
\hline \multirow[t]{5}{*}{ Medium size } & Corrected model & $15.662^{\mathrm{c}}$ & 2 & 7.831 & 2.860 & 0.083 \\
\hline & Intercept & 70.634 & 1 & 70.634 & 25.794 & 0.000 \\
\hline & Error & 49.29 & 18 & 2.738 & & \\
\hline & Total & 120.000 & 21 & & & \\
\hline & Total corrected & 64.952 & 20 & & & \\
\hline \multirow[t]{5}{*}{ Small size } & Corrected model & $44.680^{\mathrm{b}}$ & 2 & 23.340 & 10.388 & 0.001 \\
\hline & Intercept & 114.580 & 1 & 114.500 & 53.276 & 0.000 \\
\hline & Error & 51.616 & 24 & 2.151 & & \\
\hline & Total & 168.000 & 27 & & & \\
\hline & Total corrected & 96.296 & 26 & & & \\
\hline \multirow[t]{5}{*}{ Micro-company } & Corrected model & $29.103^{\mathrm{a}}$ & 2 & 14.552 & 6.016 & 0.009 \\
\hline & Intercept & 280.280 & 1 & 280.280 & 115.878 & 0.000 \\
\hline & Error & 48.375 & 20 & 2.419 & & \\
\hline & Total & 342.000 & 23 & & & \\
\hline & Total corrected & 77.478 & 22 & & & \\
\hline
\end{tabular}

Table 12. Expected time to obtain gain with loT investment (ANOVA).

\begin{tabular}{|c|c|c|c|c|c|c|}
\hline \multicolumn{7}{|c|}{$\begin{array}{l}\text { Tests of effects among subjects (Scheffe) } \\
\text { Dependent variable: When does your company expect to obtain gains with loT investment? }\end{array}$} \\
\hline Company Size & Origin & $\begin{array}{l}\text { Type III Sum of } \\
\text { Squares }\end{array}$ & $\begin{array}{l}\text { Degrees of } \\
\text { Freedom }\end{array}$ & Mean Square & $f$ & Sig. \\
\hline \multirow[t]{5}{*}{ Large size } & Corrected model & $7.673^{d}$ & 2 & 3.836 & 2.240 & 0.122 \\
\hline & Intercept & 126.429 & 1 & 126.429 & 73.834 & 0.000 \\
\hline & Error & 58.219 & 34 & 1.712 & & \\
\hline & Total & 206.000 & 37 & & & \\
\hline & Total corrected & 65.892 & 36 & & & \\
\hline \multirow[t]{5}{*}{ Medium size } & Corrected model & $10.390^{c}$ & 2 & 5.195 & 3.483 & 0.053 \\
\hline & Intercept & 22.930 & 1 & 22.930 & 15.373 & 0.000 \\
\hline & Error & 26.848 & 18 & 1.492 & & \\
\hline & Total & 51.000 & 21 & & & \\
\hline & Total corrected & 37.238 & 20 & & & \\
\hline \multirow[t]{7}{*}{ Small size } & Corrected model & $12.772^{\mathrm{b}}$ & 2 & 6.386 & 3.576 & 0.444 \\
\hline & Intercept & 57.280 & 1 & 57.280 & 32.077 & 0.000 \\
\hline & Error & 42.587 & 24 & 1.786 & & \\
\hline & Total & 101.000 & 27 & & & \\
\hline & Total corrected & 55.630 & 26 & & & \\
\hline & Corrected model & $1.770^{\mathrm{a}}$ & 2 & 0.885 & 0.525 & 0.599 \\
\hline & Intercept & 55.039 & 1 & 55.039 & 32.656 & 0.000 \\
\hline \multirow[t]{3}{*}{ Micro-company } & Error & 33.708 & 30 & 1.685 & & \\
\hline & Total & 95.000 & 23 & & & \\
\hline & Total corrected & 35.478 & 22 & & & \\
\hline
\end{tabular}




\begin{tabular}{lcc}
\hline \multicolumn{1}{c}{ Big data analytics investment } & frequency (total 108) & $\%$ \\
\hline Does your company intend to invest in BDA? & 60 & 55.6 \\
Yes & 48 & 44.4 \\
No & 35 & 32.4 \\
When does your company intend to invest in BDA? & 19 & 17.6 \\
We have already invested & 5 & 4.6 \\
We will invest in the short term (up to 1 year) & 1 & 0.9 \\
We will invest in the medium term (2 - 5 years) & 48 & 44.4 \\
We will invest in the long term (over 5 years) & & 36.1 \\
There are no investment plans & 39 & 17.6 \\
What is the main reason for the investment? & 19 & 1.9 \\
Staying competitive & 2 & 0.0 \\
Anticipating against competition & 0 & 44.4 \\
Customers' requirement & 48 & \\
Suppliers' requirement & & \\
There are no investment plans & & \\
\hline
\end{tabular}

\subsubsection{Interest in investment in Big Data Analytics}

Table 13 shows data related to the interest of respondents in BDA investment.

Table 13 shows that the emerging BDA technology is of interest to nearly 56\% of respondent, i.e., more than half of respondent companies are planning to invest in big data analytics. Thirty-five companies already invest in BDA and nineteen intend to invest in the short term, demonstrating that $90 \%$ of companies interested in investing in BDA will make this investment immediately. Maintaining competitiveness is the main reason for investing in BDA for 36\% of respondents, the second reason is to anticipate competition, response given by $16 \%$ of companies. Maintaining competitiveness is an important factor for the adoption of BDA technology.

Table 14. Gain expectation and return time for BDA.

\begin{tabular}{|c|c|c|c|c|}
\hline \multicolumn{2}{|c|}{$\begin{array}{l}\text { What is the expected gain and in what time does the company intend } \\
\text { to obtain this gain in the adoption of big data analytics? }\end{array}$} & \multirow{2}{*}{$\begin{array}{c}N \\
108\end{array}$} & \multirow{2}{*}{$\begin{array}{l}\text { Mean } \\
2.67\end{array}$} & \multirow{2}{*}{$\begin{array}{c}\text { Standard deviation } \\
2.109\end{array}$} \\
\hline \multirow{2}{*}{ All respondents } & Expected gain ${ }^{1}$ & & & \\
\hline & Expected time ${ }^{2}$ & 108 & 1.36 & 1.329 \\
\hline
\end{tabular}

$\mathrm{N}$ = Number of respondents; [1] 0 - does not apply / did not respond, 1 - no gain, 2 - little gain, 3 - medium gain, 4 - much gain e 5 - high gain. [2] 0 - does not apply / did not respond, 1 - today, 2 - short term $(<=1$ year), 3 - medium term ( $2-5$ years), 4 - long term ( $>5$ years).

Table 14 analyzes the expectation of gain with BDA investment and in what time companies believe that this gain will occur.

Table 14 shows that when all responding companies that intend to invest in BDA are considered, the expectation of gain is equal to 2.67 , which places this response close to the average gain. The expectation to obtain this gain is equal to 1.36 , which places it in the short term. When all respondents are considered, there is expectation of average gain associated with an immediate desire to obtain this gain.

Table 15 shows the ANOVA follow-up test to determine if there are significant differences in the average expected gain with BDA investment when compared to company size. The null hypothesis is that the expectation of gain with BDA investment is the same, regardless of company size.

Table 15 shows that there are significant differences in the expected gain with BDA investment for all company sizes. The null hypothesis is then rejected at 5\% significance level.

Table 16 presents the results of the ANOVA follow-up test to determine if there are significant differences in the expectation of time to obtain gains with BDA investment. The null hypothesis is that the expectation of time to obtain gains with BDA investment is the same, regardless of company size.

The results shown in Table 16 allow concluding that there are significant differences in the expected return time with BDA investment for medium-size companies. The null hypothesis for medium-size companies is rejected at 5\% significance level. For large and small companies and micro-companies, p-values greater than 
Table 15. Expected gain with BDA investment (ANOVA).

\begin{tabular}{|c|c|c|c|c|c|c|}
\hline \multicolumn{7}{|c|}{$\begin{array}{l}\text { Tests of effects among subjects (Scheffe) } \\
\text { Dependent variable: What is the expected gain with BDA investment? }\end{array}$} \\
\hline Company Size & Origin & Type 111 Sum of Squares & $\begin{array}{l}\text { Degrees of } \\
\text { Freedom }\end{array}$ & Mean Square & $f$ & Sig. \\
\hline \multirow{5}{*}{ Large size } & Corrected model & $27.056^{d}$ & 2 & 13.528 & 4.158 & 0.024 \\
\hline & Intercept & 353.168 & 1 & 353.168 & 108.550 & 0.000 \\
\hline & Error & 110.619 & 34 & 3.254 & & \\
\hline & Total & 514.000 & 37 & & & \\
\hline & Total corrected & 137.676 & 36 & & & \\
\hline \multirow{5}{*}{ Medium size } & Corrected model & $21.429^{c}$ & 2 & 10.714 & 3.894 & 0.039 \\
\hline & Intercept & 169.682 & 1 & 169.682 & 61.673 & 0.000 \\
\hline & Error & 49.524 & 18 & 2.751 & & \\
\hline & Total & 254.000 & 21 & & & \\
\hline & Total corrected & 79.952 & 20 & & & \\
\hline \multirow{5}{*}{ Small size } & Corrected model & $75.061^{\mathrm{b}}$ & 2 & 37.531 & 17.355 & 0.000 \\
\hline & Intercept & 178.235 & 1 & 178.235 & 82.418 & 0.000 \\
\hline & Error & 51.902 & 24 & 2.163 & & \\
\hline & Total & 239.000 & 27 & & & \\
\hline & Total corrected & 126.963 & 26 & & & \\
\hline \multirow{5}{*}{ Micro-company } & Corrected model & $42.036^{\mathrm{a}}$ & 2 & 21.018 & 5.772 & 0.011 \\
\hline & Intercept & 139.655 & 1 & 139.655 & 38.349 & 0.000 \\
\hline & Error & 72.833 & 20 & 3.642 & & \\
\hline & Total & 237.000 & 23 & & & \\
\hline & Total corrected & 114.870 & 22 & & & \\
\hline
\end{tabular}

Table 16. Expected time to obtain gains with BDA investment (ANOVA).

\begin{tabular}{|c|c|c|c|c|c|c|}
\hline \multicolumn{7}{|c|}{$\begin{array}{l}\text { Tests of effects among subjects (Scheffe) } \\
\text { Dependent variable: When does your company expect to obtain gains with BDA investment? }\end{array}$} \\
\hline Company Size & Origin & $\begin{array}{l}\text { Type III Sum of } \\
\text { Squares }\end{array}$ & $\begin{array}{l}\text { Degrees of } \\
\text { Freedom }\end{array}$ & Mean Square & $f$ & Sig. \\
\hline \multirow{5}{*}{ Large size } & Corrected model & $2.760^{d}$ & 2 & 1.380 & 0.830 & 0.445 \\
\hline & Intercept & 103.144 & 1 & 103.144 & 62.028 & 0.000 \\
\hline & Error & 56.538 & 34 & 1.663 & & \\
\hline & Total & 170.000 & 37 & & & \\
\hline & Total corrected & 59.297 & 36 & & & \\
\hline \multirow{5}{*}{ Medium size } & Corrected model & $14.035^{\mathrm{c}}$ & 2 & 7.017 & 4.175 & 0.032 \\
\hline & Intercept & 45.314 & 1 & 45.314 & 26.963 & 0.000 \\
\hline & Error & 30.251 & 18 & 1.681 & & \\
\hline & Total & 79.000 & 21 & & & \\
\hline & Total corrected & 44.286 & 20 & & & \\
\hline \multirow{5}{*}{ Small size } & Corrected model & $15.138^{\mathrm{b}}$ & 2 & 7.569 & 5.914 & 0.080 \\
\hline & Intercept & 45.894 & 1 & 45.894 & 35.861 & 0.000 \\
\hline & Error & 30.714 & 24 & 1.280 & & \\
\hline & Total & 77.000 & 27 & & & \\
\hline & Total corrected & 45.852 & 26 & & & \\
\hline \multirow{5}{*}{ Micro-company } & Corrected model & $11.971^{\mathrm{a}}$ & 2 & 5.986 & 6.192 & 0.080 \\
\hline & Intercept & 33.379 & 1 & 33.379 & 34.530 & 0.000 \\
\hline & Error & 19.333 & 20 & 0.967 & & \\
\hline & Total & 63.000 & 23 & & & \\
\hline & Total corrected & 31.304 & 22 & & & \\
\hline
\end{tabular}

0.05 show that there are no significant differences for the expected return time with BDA investment, then the null hypothesis is accepted for these company sizes.

\section{Conclusions and recommendations}


This work identified the degree of interest of companies in investing in emerging loT and BDA technologies aimed at applications in logistics in Brazil. These two technologies already receive investments today in more than half of responding companies. Companies have average gain expectation with BDA investment of 2.67 and loT of 2.54. Companies expect to obtain gains in the short term (up to one year) with the adoption of these two technologies. Tracking cargo stands out among applications intended for loT. Responding companies intend to use BDA to reduce operational costs, predict consumer behavior and forecasting. The main reason for the adoption of loT and BDA is the maintenance of competitiveness. The high investment in software and hardware, followed by high investment in human resources, are the most cited constraints when it comes to the adoption of emerging loT and BDA technologies.

It is possible to compare some results with those of previous studies. Regarding the adoption of loT technology, $\mathrm{Tu}$ (2018) reported that in a study of 130 managers of Taiwanese companies, the average gain expectation is 4.39 using the same scale adopted in this work, while Brazilian companies has average gain expectation of 2.54, when all respondents are considered. These results show that executives of Taiwanese companies believe that loT will bring greater gain to operations than Brazilian executives. This difference may occur due to the different economic moments of these two countries, more optimistic Thailand and more pessimistic than Brazil. The study by Rogers (2017) addresses the current stage of investment in BDA technology. The American study shows that $61 \%$ of respondents already invest in BDA technology, a value close to that of Brazilian companies, 56\%.

This survey had 108 valid questionnaires in a population of 8,000 companies (1.35\%). Although the research is valid and has experienced respondents, who occupy high positions in companies, it is desirable to apply the questionnaire to a larger number of companies, increasing the research significance. One limitation imposed by the small number of responses is the violation of the multivariate normality, usual in investigations of this type, which may cause result biases, for future studies, we suggest reapplying this study to more companies in order to verify how results vary in a larger sample. Another limitation imposed on the work is the absence of a more robust financial analysis, this absence is explained by the difficulty in obtaining such data from companies, as the majority of respondents are prevented from providing such data by confidentiality agreements. Moreover, the absence of time series in the collected data implies that causality cannot be proven.

In addition, since the research focused on intended behavior of Emerging Technologies Linked to Logistics 4.0 usage, additional study should be conducted to measure actual adoption of these technologies. Prediction of specific behavior based on intention measured before the behavior occurs may not be very accurate. Several factors such as intervening time, unforeseen environmental events, stability of intention and new information received can reduce or weaken the relationship between measured behavioral intention and observed behavior (Peter \& Olson, 1990). Then, the results between these two measurements (i.e. behavioral intention and actual behavior) must be compared to see any differences under the consideration of those stated factors.

Even facing these limitations, this study has practical implications regarding the Logistics 4.0 process as it reveals which are the important variables for the effectiveness of the Logistics 4.0 implementation.

\section{References}

Council of Supply Chain Management Professionals - CSCMP. (2018). CSCMP supply chain management definitions and glossary. Retrieved in 2019, August 15, from http://bit.do/eHW6G

Dong, Y., Carter, C. R., \& Dresner, M. E. (2001). JIT purchasing and performance: an exploratory analysis of buyer and supplier perspectives. Journal of Operations Management, 9(4), 471-483. http://dx.doi.org/10.1016/S0272-6963(00)00066-8.

Drees, J. (2016). Logistics 4.0 - tailored solutions for the future. In International Press Workshop. Chennai: Gopali \& Co.. Retrieved in 2019, August 15, from https://goo.gl/n3gjqZ

Forza, C. (2002). Survey research in operations management: a process-based perspective. International Journal of Operations \& Production Management, 22(2), 152-194. http://dx.doi.org/10.1108/01443570210414310.

Goldsby, T. J., \& Zinn, W. (2016). Technology Innovation and New Business Models: can logistics and supply chain research accelerate the evolution? Journal of Business Logistics, 37(2), 80-86. http://dx.doi.org/10.1111/jbl.12130.

Gubbi, J., Buyya, R., Marusic, S., \& Palaniswami, M. (2013). Internet of Things (loT): a vision, architectural elements, and future directions. Future Generation Computer Systems, 29(7), 1645-1660. http://dx.doi.org/10.1016/j.future.2013.01.010.

Hair, J. F. (2005). Fundamentos de métodos de pesquisa em administração. Rio de Janeiro: Bookman.

Hofmann, E., \& Rüsch, M. (2017). Industry 4.0 and the current status as well as future prospects on logistics. Computers in Industry, 89, 23-34. http://dx.doi.org/10.1016/j.compind.2017.04.002.

Kim, S., \& Kim, S. (2016). A multi-criteria approach toward discovering killer loT application in Korea. Technological Forecasting and Social Change, 102, 143-155. http://dx.doi.org/10.1016/j.techfore.2015.05.007.

Lu, Y., Papagiannidis, S., \& Alamanos, E. (2018). Internet of things: a systematic review of the business literature from the user and organizational perspectives. Technological Forecasting and Social Change, 136, 285-297. http://dx.doi.org/10.1016/j.techfore.2018.01.022.

Macaulay, J., Buckalew, L., \& Chung, G. (2015). Internet of things in logistics. DHL Trend Research, 1(1), 1-27. 
Majeed, M. A. A., \& Rupasinghe, T. D. (2017). Internet of things (loT) embedded future supply chains for industry 4.0: an assessment from an ERP-based fashion apparel and footwear industry. International Journal of Supply Chain Management, 6(1), 25-40.

Oppitz, M., \& Tomsu, P. (2018). Inventing the cloud century. Business information systems. New York: Springer International Publishing. http://dx.doi.org/10.1007/978-3-319-61161-7.

Peter, J. P., \& Olson, C. J. (1990). Consumer behavior and marketing strategy (2nd ed.). Chicago: Irwin.

Pfohl, H.-C., Yahsi, B., \& Kuznaz, T. (2015). The impact of Industry 4.0 on the supply chain. In Proceedings of the Hamburg International Conference of Logistic (pp. 32-58). Hamburg: HICL.

Richey Junior, R. G., Morgan, T. R., Lindsey-Hall, K., \& Adams, F. G. (2016). A global exploration of Big Data in the supply chain. International Journal of Physical Distribution \& Logistics Management, 46(8), 710-739. http://dx.doi.org/10.1108/1JPDLM-05-2016-0134.

Rogers, Z. (2017). Big data analytics in supply chain: tackling the tidal wave (pp. 1-6). CSCMP's Supply Chain Quarterly. Retrieved in 2019, August 15, from http://bit.do/eHXRa

Rossmann, B., Canzaniello, A., von der Gracht, H., \& Hartmann, E. (2017). The future and social impact of Big Data analytics in supply chain management: results from a Delphi study. Technological Forecasting and Social Change, 130, 135-149. http://dx.doi. org/10.1016/j.techfore.2017.10.005.

Sampieri, A. H., Collado, C. F., Lucio, M., \& Del, P. B. (2013). Metodología de la investigación (5. ed.). México D.F.: The McGraw-Hill Companies, Inc..

Strandhagen, J. O., Vallandingham, L. R., Fragapane, G., Strandhagen, J. W., Stangeland, A. B. H., \& Sharma, N. (2017). Logistics 4.0 and emerging sustainable business models. Advances in Manufacturing, 5(4), 359-369. http://dx.doi.org/10.1007/s40436-017-0198-1.

Thoben, K.-D., Wiesner, S., \& Wuest, T. (2017). "Industrie 4.0" and smart manufacturing - a review of research issues and application examples. International Journal of Automotive Technology, 11(1), 4-16.

Tiwari, S., Wee, H. M., \& Daryanto, Y. (2018). Big data analytics in supply chain management between 2010 and 2016 : Insights to industries. Computers \& Industrial Engineering, 115, 319-330. http://dx.doi.org/10.1016/j.cie.2017.11.017.

$\mathrm{Tu}$, M. (2018). An exploratory study of Internet of Things (loT) adoption intention in logistics and supply chain management - a mixed research approach. The International Journal of Logistics Management, 1-10.

Uckelmann, D., Harrison, M., \& Michahelles, F. (2011). Architecting the internet of things (pp. 1-24). USA: Springer.

Vassakis, K., Petrakis, E., \& Kopanakis, 1. (2018). Big data analytics: applications, prospects and challenges. Mobile Big Data, 10, 3-20. http://dx.doi.org/10.1007/978-3-319-67925-9_1.

Waller, M. A., \& Fawcett, S. E. (2013). Data scientist: big data, predictive analytics, and theory development in the era of a maker movement supply chain. Journal of Business Logistics, 34(4), 249-252. http://dx.doi.org/10.1111/jbl.12024.

Wang, G., Gunasekaran, A., Ngai, E. W. T., \& Papadopoulos, T. (2016). Big data analytics in logistics and supply chain management: certain investigations for research and applications. International Journal of Production Economics, 176, 98-110. http://dx.doi. org/10.1016/j.jpe.2016.03.014.

Witkowski, K. (2017). Internet of things, big data, industry 4.0 - innovative solutions in logistics and supply chains management. Procedia Engineering, 182, 763-769. http://dx.doi.org/10.1016/j.proeng.2017.03.197.

Zanella, A., Bui, N., Castellani, A., Vangelista, L., \& Zorzi, M. (2014). Internet of things for smart cities. IEEE Internet of Things Journal, 1(1), 22-32. http://dx.doi.org/10.1109/J10T.2014.2306328.

Zhong, R. Y., Newman, S. T., Huang, G. Q., \& Lan, S. (2016). Big data for supply chain management in the service and manufacturing sectors: challenges, opportunities, and future perspectives. Computers \& Industrial Engineering, 101, 572-591. http://dx.doi. org/10.1016/j.cie.2016.07.013.

Zhu, S., Song, J., Hazen, B. T., Lee, K., \& Cegielski, C. (2018). How supply chain analytics enables operational supply chain transparency: an organizational information processing theory perspective. International. Journal of Physical Distribution \& Logistics Management, 48(1), 47-68. http://dx.doi.org/10.1108/lJPDLM-11-2017-0341. 